\title{
MORPH-FREQUENCY AND CO-EXISTENCE IN CEPAEA
}

\author{
WALLACE ARTHUR \\ Department of Genetics, University of Nottingham, Nottingham NG7 2RD*
}

Received 8.v.78

\begin{abstract}
SUMmARY
The frequencies of banding morphs in Cepaea nemoralis, and in its sibling species $C$. hortensis, have been examined in relation to the relative distributions of the two species.

The frequency of unbanded $C$. nemoralis decreases significantly on moving from allopatry to sympatry. This occurs in two well-separated populations. In C. hortensis, the frequency of unbandeds also decreases in sympatry. Again the effect is shown in two different populations and is significant in both.

It is argued that this particular type of parallel variation in morphfrequency in two species, which would not result from interspecific hybridisation even if this were to occur, constitutes good evidence for natural selection (directional rather than balancing). It is stressed that the data present a strong case for each species being the selective agent acting on morph-frequency in the other; but also that the data are not consistent with the theory of character displacement.
\end{abstract}

\section{INTRODUGTION}

ONE possible evolutionary consequence of interspecific competition is divergence of the competitors in some character which has a bearing on the competitive process. Such divergence was first given a name--character displacement-by Brown and Wilson (1956), and since then there have been a number of purported examples of character displacement in natural populations (see Grant, 1972, for a review).

There are a number of problems in accepting displacing selection (resulting from competition) as the causative mechanism responsible for the morphological divergence observed. Two of the commonest problems are:

(1) The characters studied have been continuously variable ones which are not totally heritable. Considerable non-genetic variation can occur in such characters even when their heritability is high (for example shell size in Cepaea; see Cook, 1967, and Williamson et al., 1976). This problem can be obviated by studying the morph-frequency at a single locus. Theoretical and simulation studies of a single locus (in each of two species) which affects competition have been undertaken by Léon (1974) and Crozier (1974), and displacement in gene-frequency is predicted. However, no work on interspecific competitive effects on single loci appears to have been done on natural populations.

(2) Selection resulting directly from a competing species, and selection resulting from an environmental change which coincides with (and may give rise independently to) areas of sympatry are difficult to separate. This problem can be lessened, though by no means disposed of, by a

* Present address: Clinical Research Unit, Clatterbridge Hospital, Bebington, Wirral, L63 4JY. 
number of surveys on independent populations, preferably occupying different types of habitat. While many studies, including the original case of the nuthatches Sitta neumayer and S. tephronota cited by Brown and Wilson, have only dealt with one transect from allopatry to sympatry, some--notably that of Fenchel $(1975 a, b)$ on snails of the genus Hygromia - have included several.

In the present study, morph-frequency at the locus determining the presence/absence of bands on the shell of the land snails Cepaea nemoralis and $C$. hortensis was examined in relation to the relative distributions of the two species. The genetics of this locus, in both species, is well known (see Cain and Sheppard, 1957; Murray, 1963). Unbanded is dominant to banded. Where the shell is banded, various modifiers are known which alter the number and type of bands. These will not be dealt with here, as shells were classified simply as banded or unbanded.

Three well-separated populations were studied. Since the panmictic unit of Cepaea has a radius of about 30 metres (Lamotte, 1951, Murray, 1962) and all three interpopulation distances were greater than 100 miles, these populations are about as completely independent as is possible for natural populations. Further, the three types of habitat were all distinctly different from each other.

It can be seen, then, that the particular system studied here lacks the first problem mentioned above, and reduces the second. Thus it provides a good opportunity for investigating the genetic effects of interspecific competition. However, other problems remain. As with other species-pairs, interspecific competition has not been conclusively established, though in Cepaea there is considerable circumstantial evidence for it (see Cameron, 1970; Arthur, 1977). Also, while adopting a single-locus approach has its advantages, exactly how the locus chosen affects competition remains to be seen. But at the present stage of our understanding of the precise ecological effects of specific loci in natural populations, encountering this problem is inevitable.

\section{METhods AND DESGRIPTION OF SURVEY AREAS}

\section{(i) Sampling and scoring}

No sampling sites exceeded a diameter of $20 \mathrm{~m}$. Snails were sampled simply by visual search, only adults being collected. These were taken to the laboratory and not replaced. Snails were removed from their shells and discarded, the empty shells being used for scoring the banding morphs (see Cain and Sheppard, 1950).

\section{(ii) Survey areas}

(a) Cunningdale, Derbyshire: This is a steep-sided limestone dale of about $\mathrm{l} \mathrm{km}$ in length. The dale is not wooded, with the exception of the extreme southern end which was not included in the survey. It is surrounded by a quarry and agricultural land, so the Cepaea population in the dale is fairly well isolated. Fourteen samples were taken, seven containing $C$. nemoralis only, the remaining seven including both species. Fig. $\mathrm{lA}$ is an outline map of Cunningdale showing the locations of the sampling sites. 
(b) Nettlecombe, Somerset: Six samples, of which four were pure $C$. hortensis and the remaining four mixed, were taken from the hedges bordering a large field in the Nettlecombe area of Somerset. Locations of the sampling sites are shown in fig. 1B. No snails were found in the field itself. In this survey, a different method of sampling was employed. The hedges and banks were searched with a gardening fork. This method was necessary
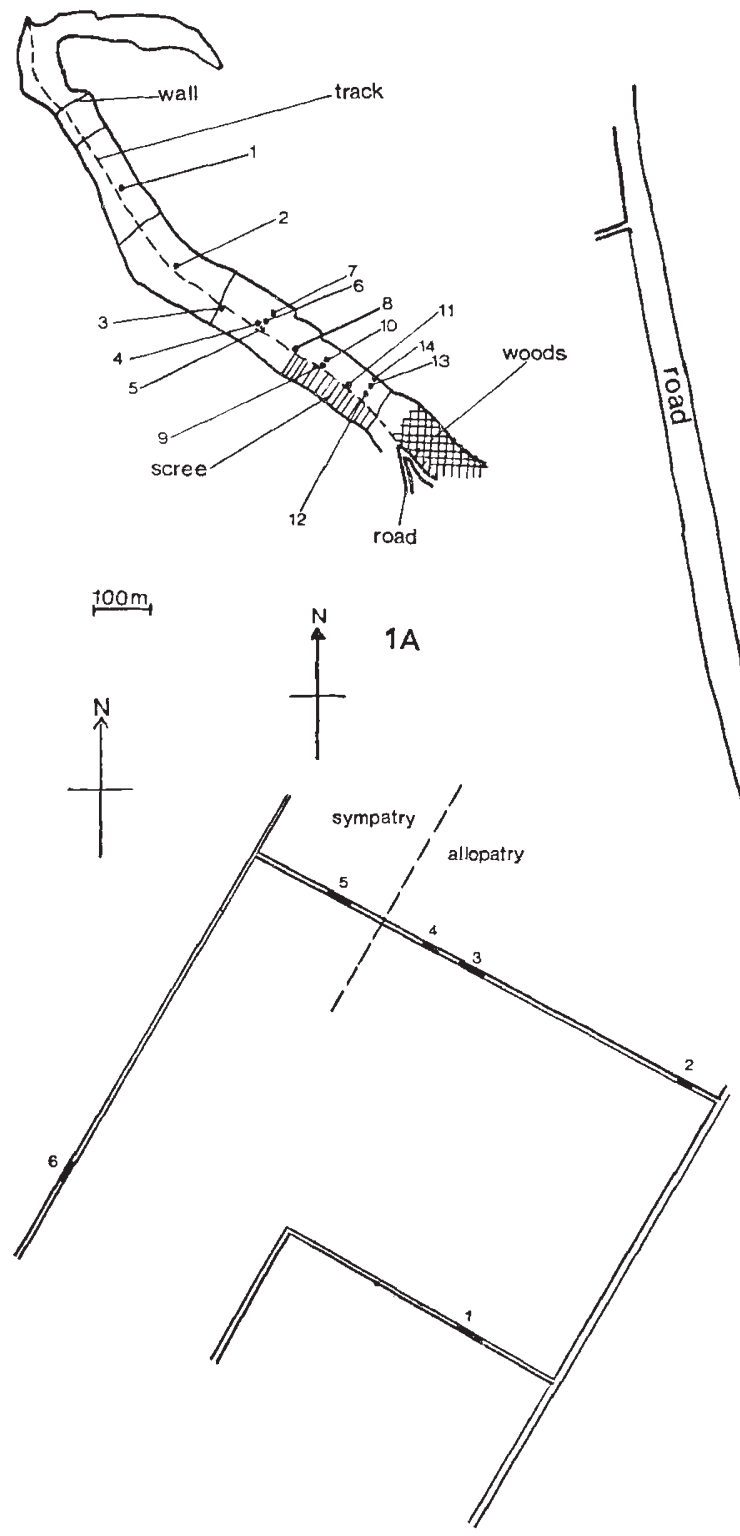

$1 \mathrm{~B}$
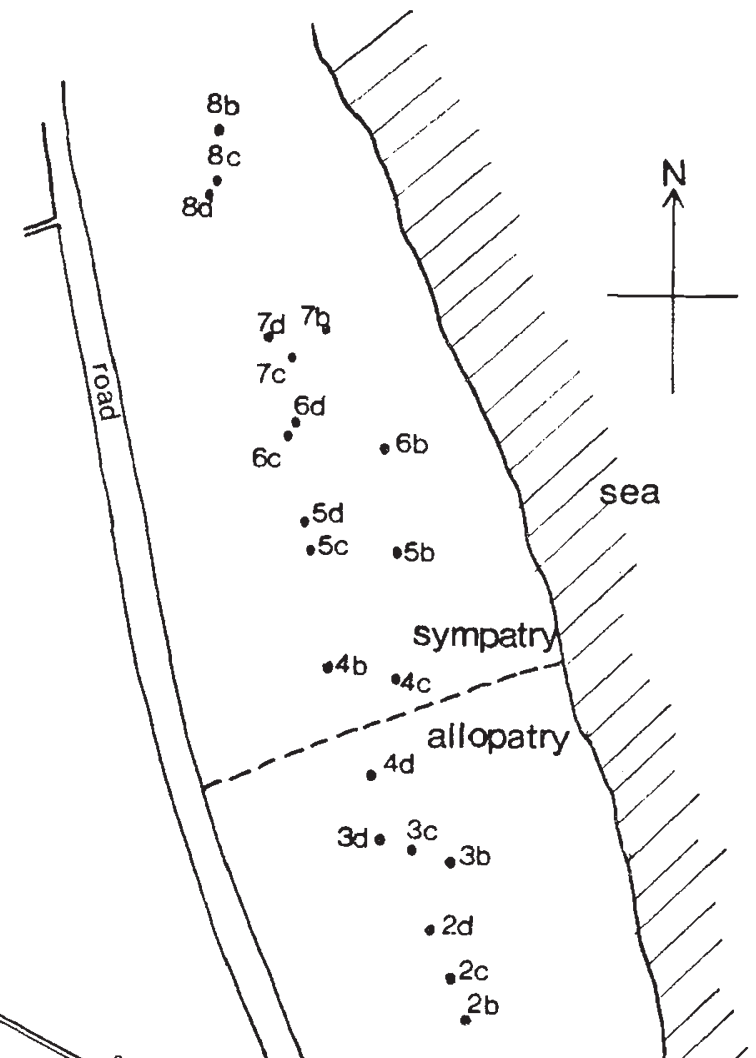

$1 c$.

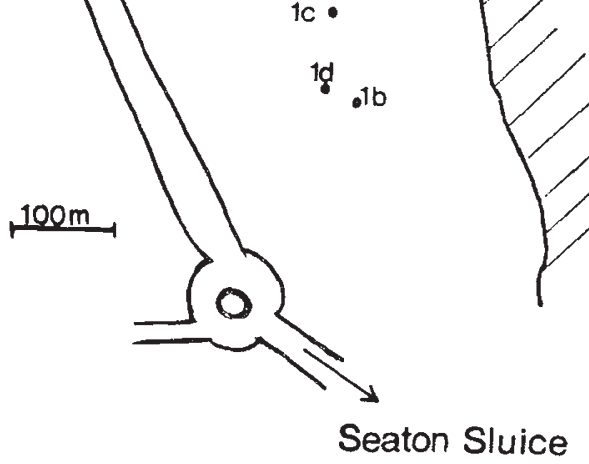

$1 \mathrm{C}$

FIG. 1.-The areas surveyed, with locations of the sampling sites. 1A: Cunningdale; 1B: Nettlecombe; 1C: Seaton Sluice. Note.-In the Seaton Sluice survey (b) (c) and (d) refer to separate habitat categories. See table 3 for details. 
since the survey was carried out immediately after the 1976 drought, and most of the snails were found buried a few centimetres in the soil.

(c) Seaton Sluice, Northumberland: A continuous line of sand-dunes stretches for nearly $1.5 \mathrm{~km}$ northwards from the town of Seaton Sluice. The dunes, together with some more stabilised habitat, are bounded by a main road, then agricultural land, on the west (and by the sea on the east). Twenty-four samples were taken, 14 containing both species and 10 containing only $C$. nemoralis. The locations of the sampling sites are shown in fig. $1 \mathrm{C}$.

\section{Results}

The data obtained from the three surveys are displayed in tables 1-3. Two approaches to the analysis may be taken. Firstly, the mixed and singlespecies groups of samples from a survey can be compared-with respect to their morph-frequencies-regardless of the exact positions of individual samples. Secondly, the change in morph-frequency on approaching

TABLE 1

\begin{tabular}{|c|c|c|c|c|c|c|}
\hline \multirow[b]{2}{*}{$\begin{array}{c}\text { Sample } \\
\text { no. }\end{array}$} & \multicolumn{5}{|c|}{ Data on the Cunningdale populations } & \multirow[b]{2}{*}{$\begin{array}{l}\text { Freq. of } \mathrm{B} \\
\text { in C. hort. }\end{array}$} \\
\hline & $\begin{array}{l}\text { No. of } \\
\text { C. nem. }\end{array}$ & $\begin{array}{l}\text { No. of } \\
\text { C. hort. }\end{array}$ & Total & $\begin{array}{c}\text { Allopatry } \\
\text { or Sympatry? }\end{array}$ & $\begin{array}{l}\text { Freq. of } \mathrm{B}^{0} \\
\text { in } C . \text { nem. }\end{array}$ & \\
\hline 1 & 41 & 0 & 41 & A & $92 \cdot 7$ & - \\
\hline 2 & 15 & 0 & 15 & A & $86 \cdot 7$ & - \\
\hline 3 & 26 & 0 & 26 & A & $46 \cdot 2$ & - \\
\hline 4 & 20 & 0 & 20 & A & $50 \cdot 0$ & - \\
\hline 6 & 26 & 0 & 26 & $\mathrm{~A}$ & 76.9 & - \\
\hline 7 & 31 & 0 & 31 & A & 51.6 & - \\
\hline 13 & 10 & 0 & 10 & A & 62.5 & - \\
\hline 5 & 32 & 2 & 34 & $S$ & $50 \cdot 0$ & $*$ \\
\hline 8 & 42 & 9 & 51 & $\mathrm{~S}$ & 54.8 & $11 \cdot 1$ \\
\hline 9 & 19 & 31 & 50 & $S$ & $36 \cdot 8$ & 6.5 \\
\hline 10 & 19 & 2 & 21 & $\mathbf{S}$ & $42 \cdot 1$ & $*$ \\
\hline 11 & 34 & 33 & 67 & $S$ & $52 \cdot 9$ & 0.0 \\
\hline 12 & 12 & 2 & 14 & $\mathrm{~S}$ & $41 \cdot 7$ & $*$ \\
\hline 14 & 19 & 3 & 22 & $S$ & $47 \cdot 4$ & $*$ \\
\hline
\end{tabular}

* Indicates sample too small to obtain reliable estimate. $\mathrm{B}^{0}$ refers to unbandeds.

TABLE 2

Data on the Nettlecombe populations

$\begin{array}{cccccccc}\begin{array}{c}\text { Sample } \\ \text { no. }\end{array} & \begin{array}{c}\text { Sample } \\ \text { rank }\end{array} & \begin{array}{c}\text { No. of } \\ \text { C. nem. }\end{array} & \begin{array}{c}\text { No. of } \\ \text { C. hort. }\end{array} & \text { Total } & \begin{array}{c}\text { Allopatry } \\ \text { or Sympatry? }\end{array} & \begin{array}{c}\text { Freq. of B } \\ \text { in C. nem. }\end{array} & \begin{array}{c}\text { Freq. of B } \\ \text { in C. hort. }\end{array} \\ 1 & -4 & 0 & 52 & 52 & \text { A } & - & 13.3 \\ 2 & -3 & 0 & 40 & 40 & \text { A } & - & 21.2 \\ 3 & -2 & 0 & 60 & 60 & \text { A } & - & 35 \cdot 0 \\ 4 & -1 & 0 & 34 & 34 & \text { A } & - & 55 \cdot 9 \\ 5 & +1 & 15 & 23 & 38 & \text { S } & 0 \cdot 0 & 8.7 \\ 6 & +2 & 6 & 42 & 48 & \text { S } & 0.0 & 4.8\end{array}$

* Samples are ranked in order from the boundary between allopatry and sympatry, allopatric samples being designated as negative ranks. 
TABLE 3

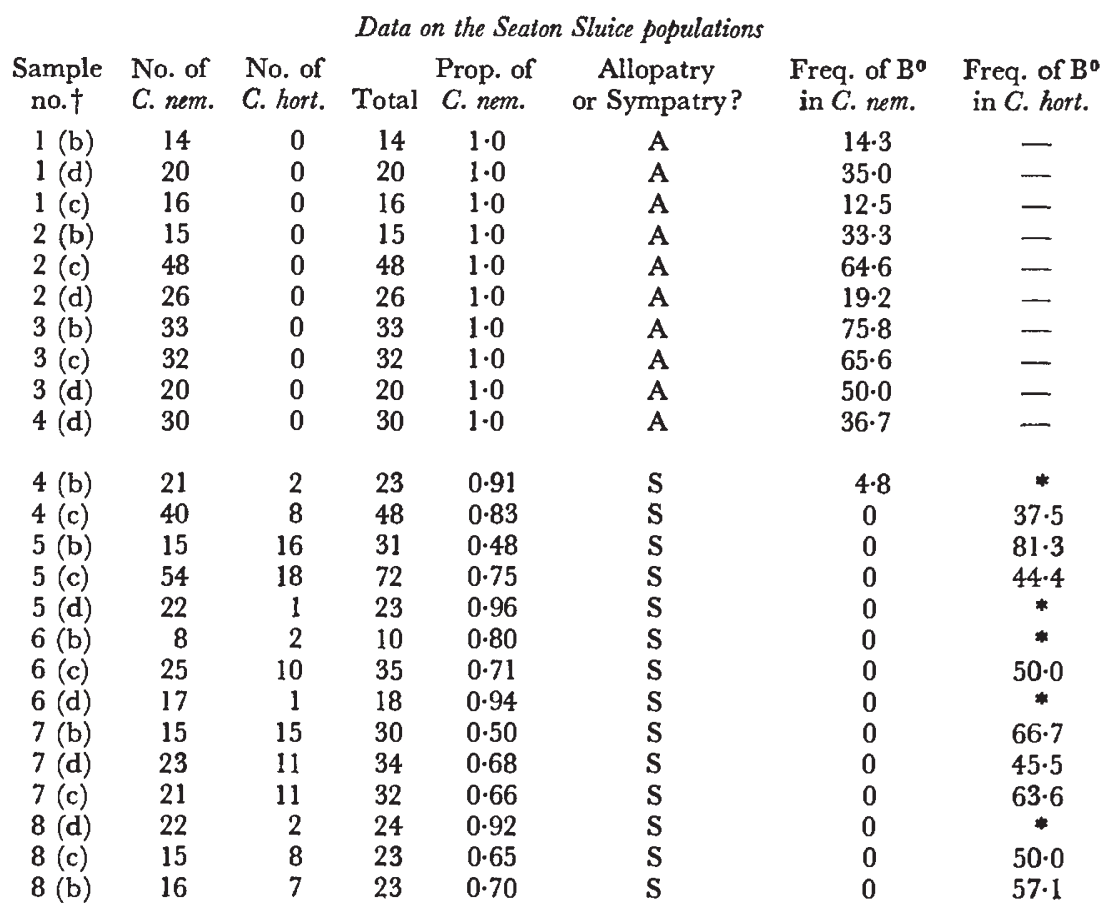

* indicates sample too small to obtain reliable estimate.

$\dagger$ (b) (c) and (d) refer to habitat categories differing in the proportion of marram grass and herbs. Kruskal-Wallis anova revealed no effect whatsoever of habitat on the frequency of unbandeds.

sympatry (or allopatry) can be contrasted with the change at the boundary between the two zones. This latter approach is only possible where a linear type of habitat is occupied, with the boundary between allopatry and sympatry occurring at a known point along it (or where the samples form a transect across such a boundary), so it is not applicable to the Gunningdale survey.

The results of comparing morph-frequencies of mixed and single-species groups of samples are shown in table 4 . Note that in the Nettlecombe survey " single-species" refers to $C$. hortensis while in the others it refers to

\section{TABLE 4}

Comparison of the frequency of unbandeds in allopatry and sympatry

\begin{tabular}{|c|c|c|c|c|c|c|}
\hline Area & Species & $\begin{array}{l}\text { No. of } \\
\text { samples }\end{array}$ & $\begin{array}{l}\text { Statistical* } \\
\text { parameter }\end{array}$ & Value & $\begin{array}{l}\text { Increase or } \\
\text { decrease in } \\
\text { sympatry? }\end{array}$ & $\mathbf{P}$ \\
\hline Cunningdale & C. nem. & 14 & $t$ & $2 \cdot 589$ & Decrease & $<0.05$ \\
\hline Nettlecombe & C. hort. & 6 & $U$ & $0 \cdot 0$ & Decrease & $\simeq 0.07$ \\
\hline Seaton Sluice & C. nem. & 24 & $U$ & $0 \cdot 0$ & Decrease & $<0.001$ \\
\hline
\end{tabular}

* The Mann-Whitney " $U$ " was used instead of the $t$-test in two cases-because of nonnormality (Seaton Sluice) and the small number of samples (Nettlecombe). In Cunningdale, where the $t$-test was used, the frequency of unbandeds was arcsin transformed. 
C. nemoralis. It can be seen that in all three areas there is a decrease in the frequency of unbandeds in sympatry. This decline is significant in Cunningdale, very highly significant at Seaton Sluice, and bordering on significance at Nettlecombe. In fact, the probability level obtained from the Nettlecombe data is as close to formal significance as is possible with only six samples and this kind of test.

Turning to the second method of analysis, fig. 2 shows the frequency of unbanded $C$. hortensis at Nettlecombe plotted against the position of each

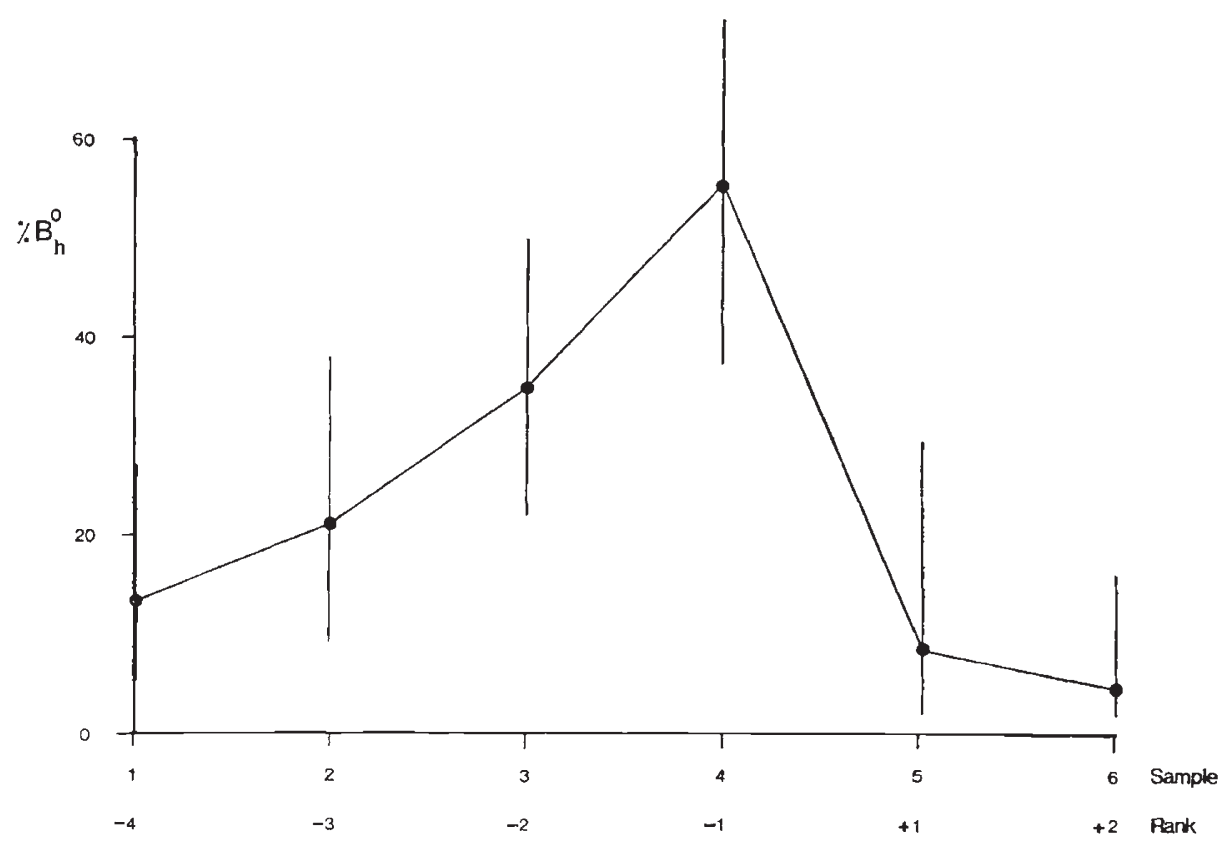

FIG. 2.-The variation in frequency of unbanded C. hortensis $\left(\% \mathrm{~B}_{\mathrm{h}}^{-0}\right)$ in relation to species-distributions at Nettlecombe. Note. - The samples were related to the allopatry/sympatry border by rank rather than physical distance. This removes the problem of whether to measure distances directly or along the hedges. Bars indicate 95 per cent confidence limits.

sample relative to the boundary between allopatry and sympatry. It can be seen that while there is an upward trend in unbandeds as sympatry is approached, there is a marked decline in frequency on entering sympatry $\left(\chi^{2}=11 \cdot 178 ; P<0.001\right)$. No other comparison of consecutive samples (by $\chi^{2}$ ) reveals a significant difference.

At Seaton Sluice (see fig. 3) there again appears to be an upward trend in the frequency of unbandeds, this time in $C$. nemoralis, on approaching sympatry ( $t$-test on regression coefficient, with frequency arcsin-transformed, gives $t=2 \cdot 104 ; P \simeq 0 \cdot 07)$. However, on entering the sympatric area, the frequency of unbandeds again suffers a marked decline. In fact, in this case the effect is so great that there was only one unbanded $C$. nemoralis among all 292 shells of that species collected from the sympatric region.

An ideal field situation for this type of study would be a population which was initially pure $C$. nemoralis, then mixed, the mixed population giving way on its other side to pure $C$. hortensis. This would enable the 


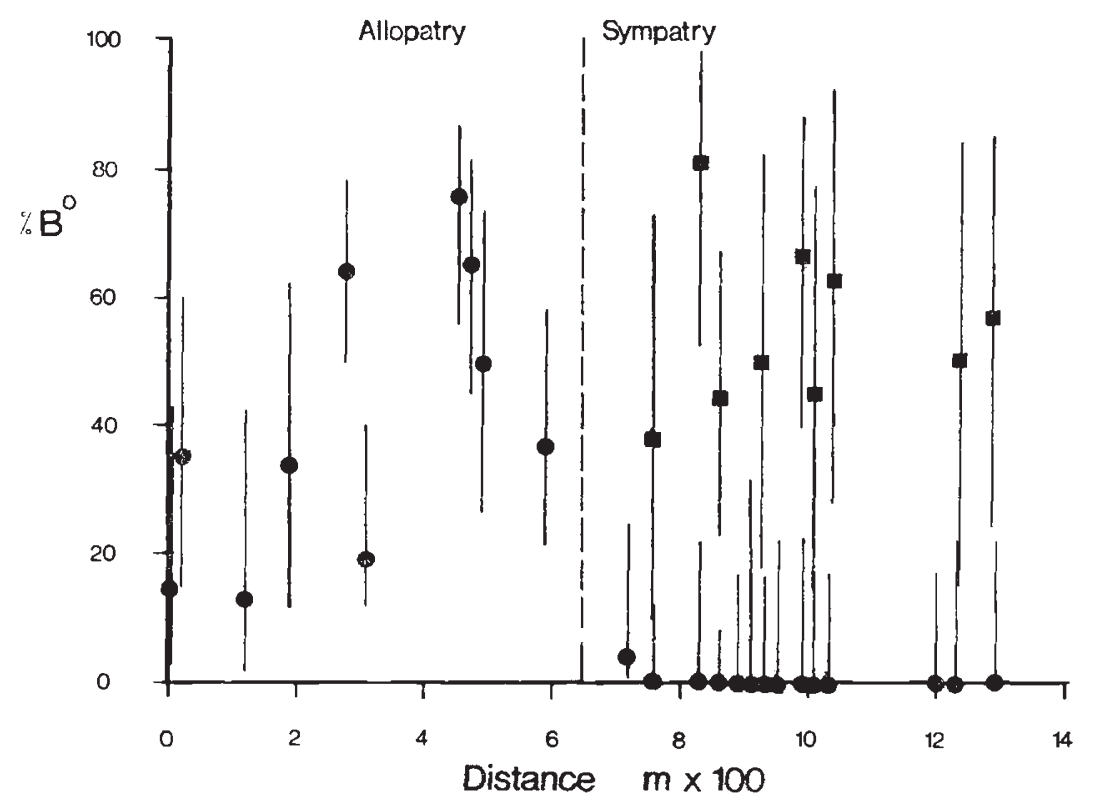

Frg. 3.- The variation in frequency of unbandeds $\left(\% \mathrm{~B}^{0}\right)$ at Seaton Sluice. Note.-(1) $=C$. nemoralis; $=C$. hortensis. (2) Distance is measured northwards from sample 1(b). (3) Bars indicate 95 per cent confidence limits.

change in morph-frequency in both species to be examined on moving from allopatry to sympatry. No such situation has yet been found. However, in the Seaton Sluice survey, there were sufficient mixed-species samples to permit a study of variation in the frequency of unbanded $C$. hortensis within the sympatric area. Specifically, if this frequency is plotted against the proportion of $C$. nemoralis in the total sample, this should be equivalent to an allopatric/sympatric comparison. In both cases, there is an increase in the intensity of interspecific competition from the viewpoint of $C$. hortensis. In the case of going from allopatry to sympatry, the increase is from zero, while in the case of going into " deeper sympatry" it is from some unspecified level. The results are shown plotted in this manner in fig. 4. The correlation coefficient (both variables having been arcsin-transformed) $r=-0.89$; $P<0.005$. Thus it seems that within the Seaton Sluice survey, as well as in general, there are parallel-rather than divergent-effects in the two species.

Two cautionary comments are necessary. The first relates specifically to the data as treated in fig. 4. The reliability of species-frequency estimates may well be lower than that of morph-frequency estimates due to behavioural differences between species (see Clarke, 1962b). Tests on two sampling sites in Gunningdale, each on two occasions, revealed no significant difference in species-frequency at either site; but no similar tests were carried out in the other surveys. It should be stressed, though, that sampling was carried out during damp weather when both species are most active and estimates likely to be most reliable. The second point of caution is a more general one. Although the three surveys were well separated, sampling sites within surveys were often close together and so may not be completely independent. 
This is a problem of all detailed surveys of this kind and cannot be disposed of, so it should be kept in mind when interpreting the results.

It should perhaps be mentioned that shell size and morph-frequency at the locus determining the base-colour of the shell were also investigated. Neither showed any consistent association with species-distributions. The data on these variables may be found in Arthur (1977).

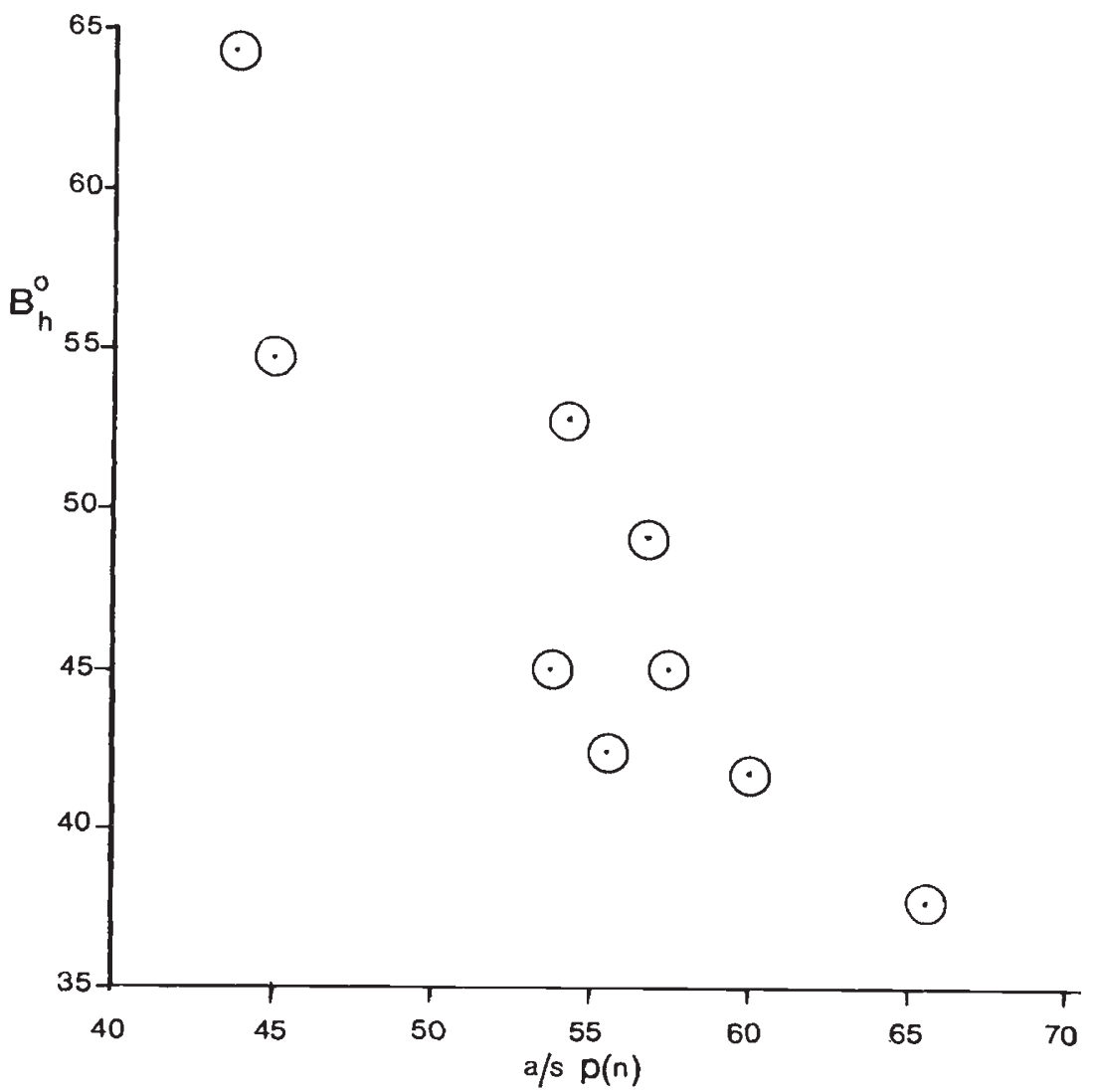

Fig. 4.-Variation in frequency of unbanded $C$. hortensis $\left(B_{\mathrm{h}}^{0}\right)$ in relation to the speciesfrequency of $C$. nemoralis $(\mathrm{a} / \mathrm{s} \mathrm{p}(\mathrm{n}))$. Note.-Both variables are arcsin-transformed in this figure.

\section{Discussion}

It is clear that the results presented here do not, in general, show interspecific displacement in morph-frequency. The frequency of unbanded $C$. nemoralis decreases in sympatry both in Cunningdale and at Seaton Sluice. In the former area, the frequency of unbandeds in $C$. hortensis is lower than in $C$. nemoralis, while in the latter it is higher. Further, the change in the frequency of unbanded $C$. hortensis on moving into sympatry (in both Nettlecombe and Seaton Sluice populations) is in the same direction as that in $C$. nemoralis. So rather than displacement or convergence, there seem to be parallel effects in the two species. 
Three questions which arise from this work are:

1. Is the reduction in the frequency of unbandeds in sympatry a general effect?

2. If so, why has it been undetected in previous surveys of Cepaea populations?

3. What is the mechanism causing the change in morph-frequency?

As regards the generality of the effect, it has already been seen that a significant reduction in the frequency of unbandeds in sympatry occurs in four populations: two of $C$. nemoralis and two of $C$. hortensis. Only one further survey of neighbouring and clearly-defined allopatric and sympatric populations has been conducted. In this, the frequency of unbandeds in allopatric $C$. nemoralis was zero (some samples) or near zero (the rest). Thus a significant decline in sympatry could hardly be expected and was not found; nor was there a significant increase. Additional surveys are being planned, and the results of these should help to evaluate further the generality of the effect.

If the reduction in frequency of unbandeds in sympatry is a general phenomenon, it should occur in a considerable proportion of further appropriate surveys, and a significant change in morph-frequency in the opposite direction would not be expected to occur anywhere (though see below). However, the effect would not be expected in all surveys, for three reasons. Firstly, not all sympatric populations are necessarily competing. This will depend largely on the structure of the environment. Secondly, the selective differential between bandeds and unbandeds may be dependent on the alleles present at loci elsewhere in the genome-i.e. there may be epistatic interaction. Thirdly, in some areas, some factor of the "sympatric habitat" may select in the opposite direction to the competitive effect-i.e. in favour of unbandeds. In fact, combining this with the possibility of no competition in some mixed populations, a rise in the frequency of unbandeds in sympatry might occur. This last point--namely the compounding of different selective forces-has been stressed recently in relation to Cepaea by Jones et al. (1977).

Since there have been numerous surveys of morph-frequency at the banding locus in Cepaea, it initially seems surprising that, if indeed the effect described here is a general one, it has not been described before. However, most studies have until now dealt only with single-species populations, usually of $C$. nemoralis. A few have dealt with mixed-species populations (e.g. Clarke, 1962a, b; Carter, 1967), and none at all have concentrated specifically on a comparison of neighbouring areas of allopatry and sympatry, though Greenwood (1974) includes one such comparison. Thus the lack of detection of the kind of effect described here is not as surprising as it first appeared.

Also, the negative correlation between the frequencies of "yellow effectively unbandeds" in C. nemoralis and in C. hortensis described by Glarke $(1962 a, b)$ might be due to competitive selection rather than apostatic selection, as Clarke himself has pointed out. More specifically, as the species-frequency of $C$. hortensis rises, the frequency of unbanded $C$. nemoralis should fall. However, if the species-frequency of $C$. hortensis is increasing this means of course that the species-frequency of $C$. nemoralis is declining, so the frequency of unbandeds in $C$. hortensis should increase. Thus there 
would be a negative correlation between the frequency of unbanded $C$. nemoralis and unbanded $C$. hortensis. Taking a subset of the unbanded category, such as yellow effectively unbanded, the correlation might still hold.

The third question raised earlier is-what causes the frequency of unbandeds to decline in sympatry? There are several components to this question. The parallel effects in different areas and, more importantly, in the two species point strongly to the action of natural selection. Lewontin (1974) has stressed that parallel changes in gene-frequency in separate species provide one of the strongest lines of evidence for natural selection, provided of course that the species do not hybridise. Hybridisation in Cepaea is very rare, though a few examples have been reported (see Lang, 1908). Regardless of this, we have here a rather unusual kind of parallel variation in that the selective agent appears to be the alternative species. The overall pattern resulting from this kind of selection, as described here, could not be explained by the alteration of morph-frequency in one species through some agency, coupled with interspecific hybridisation. Thus this kind of pattern provides particularly good evidence for the selective alteration of morph-frequencies.

The difficulty in distinguishing between selection resulting directly from a competing species and that resulting from some environmental factor associated with the presence of that species was mentioned earlier. The very different nature of the three survey areas described here (limestone dale, banks beneath hedgerows, and dunes) certainly lessens the likelihood of the latter type of selection. A further argument in this direction is as follows. If there is any consistent difference in environmental conditions such as temperature or humidity between allopatric and sympatric areas, the latter would be expected to be intermediate in whatever environmental variable is concerned between pure $C$. nemoralis and pure $C$. hortensis areas. Thus a shift from allopatry to sympatry for $C$. nemoralis would, in environmental terms, be in the opposite direction to an allopatric-to-sympatric shift for $C$. hortensis. So the morph-frequencies should, on an "environmental selection" basis, move in opposite directions. As has been seen, the reverse is the case.

The evidence seems, then, to favour natural selection resulting directly from the presence of the congeneric species as the cause of the morphfrequency variation observed. Since the direction of change in the frequency of unbandeds in either species appears to be independent of the morphfrequency in the other, simple competitive inferiority of unbanded snails would seem to be the simplest explanation. Exactly why unbanded snails should be weaker interspecific competitors than banded ones remains to be established, and this represents the major weakness of the case presented here. It is possible to hypothesise mechanisms of selection based on effects of the bands themselves. Bands can alter the shell's thermal properties (Heath, 1975) and so may indirectly affect the behaviour-patterns of the snail. However, the banding locus may be pleiotopic and/or tightly linked to another polymorphism affecting interspecific competitive ability. Selection acting via these routes is equally possible.

On a more general level, this study raises the question of whether genefrequencies at loci affecting interspecific competition tend usually to diverge in sympatry (i.e. single-locus character displacement) or whether selection more often acts in parallel on the two species concerned. Presumably, 
which of these two patterns of variation occurs at a particular locus will depend on the exact manner in which that locus affects the competitive process. More specifically, it will depend on whether the alleles rank along an axis of similarity to the congener, or along an axis which is essentially an efficiency gradient. Clearly, the answer to this sort of question is a long way off. However, the relative generality of interspecific displacement and alternative modes of competitively induced evolution is of importance in understanding how the competitive process limits species-diversity, so the answer is worth pursuing.

Acknowledgements.-Dr Cuillin Bantock, Mr David Horsley and Dr Steve Jones helped in locating suitable study areas. Sampling in Somerset was done in conjunction with $\mathrm{Mr}$ Richard Probert. The ideas were discussed in detail with Professor Bryan Clarke. I am grateful to Professor Clarke, and to Professor John Maynard Smith, for critically reading the manuscript. The work was done while I held a postgraduate studentship from the Northern Ireland Department of Education.

\section{REFERENCES}

ARTHUR. W. 1977. Studies on the relationship between environmental heterogeneity, natural selection and interspecific competition. Ph.D. thesis, University of Nottingham. BRown, w. L., AND Wilson, E. o. 1956. Character displacement. Syst. Zool., 5, 49-64.

CAIN, A. J., AND SHEPPARD, P. M. 1950. Selection in the polymorphic land snail Cepaea nemoralis. Heredity, 4, 275-294.

CAIN, A. J., AND SHEPPARD, P. M. 1957. Some breeding experiments with Cepaea nemoralis (L). 7. Genet., 55, 195-199.

CAMERON, R. A. D. 1970. Differences in the distributions of three species of helicid snail in the limestone district of Derbyshire. Proc. Roy. Soc. Lond. B., 176, 131-159.

CARTER, M. A. 1967. Selection in mixed colonies of Cepaea nemoralis and Cepaea hortensis. Heredity, 22, 117-139.

CLARKE, B. C. 1962a. Balanced polymorphism and the diversity of sympatric species. In Taxonomy and Geography, ed D. Nichols. Syst. Ass. Publ. No. 4.

ClARKE, B. C. 1962b. Natural selection in mixed populations of two polymorphic snails. Heredity, 17, 319-345.

Cook, L. M. 1967. The genetics of Cepaea nemoralis. Heredity, 22, 397-410

CRozIER, R. H. 1974. Niche shape and genetic aspects of character displacement. Amer. Zool., 14, 1151-1157.

FENCHEL, T. 1975a. Factors determining the distribution patterns of mud snails (Hydrobiidae). Oecologia, 20, 1-17.

FENCHEL, T. 1975b. Character displacement and coexistence in mud snails (Hydobiidae) Oecologia, 20, 19-32.

GRANT, P. R. 1972. Convergent and divergent character displacement. Biol. F. Linn. Soc., 4, 39-68.

GREeNwOOD, J. J. D. 1974. Visual and other selection in Cepaea: a further example. Heredity, 33, 17-31.

HEATH, D. J. 1975. Colour, sunlight and internal temperatures in the land snail Cepaea nemoralis (L). Oecologia, 19, 29-38.

Jones, J. s., Leith, B. H., AND RAWlings, P. 1977. Polymorphism in Cepaea: a problem with too many solutions? Ann. Rev. Ecol. Syst., 8, 109-143.

LAмотTE, м. 1951. Recherches sur las structure génétique des populations naturelles de Cepaea nemoralis (L). Bull. Biol. Fr. Belg., Suppl., 35, 1-239.

LANG, A. 1908. Úber die Bastarde von Helix hortensis Müller und Helix nemoralis L. Eine Untersuchung fur experimentallen Veverbungslehre. Festschr. Univ. Fena.

LÉON, J. A. 1974. Selection in contexts of interspecific competition. Amer. Nat., 108, 739-757.

LEWontrn, R. C. 1974. The Genetic Basis of Evolutionary Change. Columbia University Press, N.Y.

$41 / 3-G$ 
MURRAY, J. J. 1962. Some factors affecting gene-frequencies of Cepaea. D.Phil thesis, University of Oxford.

MURRAY, J. J. 1963. The inheritance of some characters in Cepaea hortensis and Cepaea nemoralis (Gastropoda). Genetics, 48, 605-615.

willtamson, P., Cameron, R. A. D., AND CARTER, M. A. 1976. Population density affecting adult shell size of the snail Cepaea nemoralis L. Nature, 263, 496-497. 